\title{
Sotos Syndrome Presenting without Gigantism
}

\section{Vykuntaraju K Gowda $^{1}$ (D) Balamurugan Nagarajan ${ }^{1} \cdot$ Sanjay K Shivappa ${ }^{2} \cdot$ Naveen Benakappa $^{2}$}

Received: 26 March 2020 / Accepted: 10 June 2020 / Published online: 16 June 2020

(C) Dr. K C Chaudhuri Foundation 2020

To the Editor: Sotos syndrome is an autosomal dominant disorder characterized by statural overgrowth, distinctive appearance (down slanting palpebral fissures, long narrow face and chin, broad forehead, dolichocephalic large head), and intellectual disability [1]. Prevalence of Sotos syndrome is 1 in 14,000 live births [1], however it is under recognized. Here we report a child with Sotos syndrome with normal height, weight, and head size. A 3-y-old female child presented with hyperactivity noted since 18 mo of age. Child was born by cesarean section (indication- large baby) with a birth weight of $4.2 \mathrm{~kg}$, but length and head circumference at birth were not documented. Child had delay in attainment of fine motor, language, and social milestones. Her first tooth erupted at fifth month of life, but parents did not remember order of teeth appearance. On examination, weight, length and head circumference measured and plotted on World Health Organization growth charts were $14.5 \mathrm{~kg}$ (just above the zero $\mathrm{Z}$ score curve), $98 \mathrm{~cm}$ (between zero to $2 \mathrm{Z}$ score curve), $49 \mathrm{~cm}$ (exactly on 50th percentile curve which is equal to zero $\mathrm{Z}$ score) respectively and were found to be normal for age. She was hyperactive, has dolichocephaly, broad forehead, pointed chin, anteverted ears, hypertelorism, long extremities, hypermobile joints, and normal power. Pes-planus and scoliosis were absent. Mother also had similar dysmorphic features. In view of distinct facial features and child being large of gestational age at birth, a diagnosis of Sotos syndrome was considered and hence X-ray of left wrist was done to assess bone age which was advanced (6 y). Echocardiography and ultrasonography of abdomen were normal. CT brain showed

Vykuntaraju K Gowda

drknvraju08@gmail.com

1 Department of Pediatric Neurology, Indira Gandhi Institute of Child Health, Bangalore, India

2 Department of Pediatric Medicine, Indira Gandhi Institute of Child Health, Bangalore, India ventriculomegaly, persistent septum pellucidum, prominent occipital horn and trigone. Targeted next generation sequencing showed pathogenic variant in NSD1 gene in heterozygous status for autosomal dominant disease. The variant was NM_022455.4:c.1239_3796 + 2del in exon 5. The same deletion was confirmed by MLPA in both index child and mother. The child was treated with multidisciplinary team with behavioral therapy, occupational therapy, and speech therapy. Genetic counseling and parental evaluation were advised.

Sotos syndrome is clinically diagnosed usually based on macrocephaly and gigantism [2]. Height may normalize in adulthood, but macrocephaly is usually present at all ages [3]. Less than $10 \%$ of individuals with Sotos syndrome do not have growth parameters above the 98th centile [4]. To conclude, Sotos syndrome can present with hyperactivity and it should be considered even in absence of macrocephaly and gigantism. Advanced bone age could be a surrogate marker aiding in early diagnosis.

\section{Compliance with Ethical Standards}

Conflict of Interest None.

\section{References}

1. Tatton-Brown K, Cole TRP, Rahman N. Sotos Syndrome. 2004 Dec 17 [Updated 2015 Nov 19]. In: Pagon RA, Adam MP, Ardinger HH, Wallace SE, Bean LJH, Stephens K , et al., editors. GeneReviews ${ }^{\circledR}$ [Internet]. Seattle (WA): University of Washington, Seattle; 1993-2019.

2. Tatton-Brown K, Douglas J, Coleman K, et al. Genotype-phenotype associations in Sotos syndrome: an analysis of 266 individuals with NSD1 aberrations. Am J Hum Genet. 2005;77:193-204.

3. Agwu JC, Shaw NJ, Kirk J, Chapman S, Ravine D, Cole TR. Growth in Sotos syndrome. Arch Dis Child. 1999;80:339-42.

4. Cole TR, Hughes HE. Sotos syndrome: a study of the diagnostic criteria and natural history. J Med Genet. 1994;31:20-32.

Publisher's Note Springer Nature remains neutral with regard to jurisdictional claims in published maps and institutional affiliations. 